\title{
Feminising Innovation: Challenges in Science and Technology Studies
} (STS)

\author{
Gabriele Griffin ${ }^{1 *}$
}

Published: September 1, 2021

\begin{abstract}
This article explores why innovation, conventionally associated with the masculine (e.g., Andersson et al., 2012; Lindberg, 2012), might also be framed as feminine, indeed on occasion feminist. It does so via an exploration of the embedding of a new academic discipline, in this instance Digital Humanities, in existing higher education institutions in the Nordic countries. Drawing on qualitative research conducted in 201718 with Digital Humanities practitioners in Finland, Sweden and Norway, this article argues that the feminisation of innovation in higher education institutions can lead to the material and symbolic marginalisation of those disciplines, with specific consequences both for their practitioners and for those disciplines. As part of this, the article analyses how innovation can be considered both desirable and disruptive (innovation as such constitutes a disruptive technology), and utilises Fiona Mackay's (2014) notions of 'embedded newness' and the 'liability of newness' to explore the gendered implications of the feminising of innovation.
\end{abstract}

Keywords: Digital Humanities, feminising innovation, nested newness, Nordic countries, innovation and gender

\section{INTRODUCTION}

Innovation and innovation studies have come to the fore in the past twenty years or so, and with this, a concern regarding the role of gender in innovation (Ahl and Marlow, 2012; Alsos et al., 2013; Marlow and McAdam, 2012; Pettersson and Lindberg, 2013). The discussion of that role has gradually broadened from quasi-essentialist preoccupations with women and men as sexed entities in innovation, to a consideration of the context, processes and practices of innovation as being gendered (Alsos et al., 2013; Blake and Hanson, 2005; Lindberg et al., 2015; Pecis, 2016). It has also gradually broadened from a focus on male-dominated industries and technology to including social innovation and domains dominated by women such as healthcare (André, 2013; Lindberg et al., 2016; Maestiprietri, 2017; Pecis and Priola, 2019; Sundin, 2012). All of this work has shown that gender in innovation is a highly complex multi-facetted issue.

Innovation studies shares the concern regarding the role of gender with science and technology studies (STS) where questions of women's under-representation at various levels and in diverse domains have dominated discussions (such as Schiebinger, 1999; Ernst and Horwath, 2013; Fox et al., 2017; Hearn and Husu, 2011; Henwood and Miller, 2001; Wajcman, 2000, 2007, 2010). The discussion about women's under-representation in science and technology has led to extensive debates about measures to combat such under-representation and their relative effectiveness (such as Buse, 2018; Nnachi and Okpube, 2015; Roberts, 2014; Siann and Callaghan, 2001). At the same time new areas of enquiry such as 'Medical Humanities', 'Health Technology' and 'Digital Humanities' have emerged which conjoin technology, traditionally male dominated, and disciplines (e.g., humanities, health care) that have traditionally been female dominated. These innovations in the academic domain to some extent confound binarist assumptions about gender and disciplinary preferences, but they also produce certain gendered problematics as I shall explore below. The confounding of binarist assumptions about gender occurs as a function of the fact that in these emerging domains women frequently, but not invariably, occupy both majority and leadership positions - two positions they supposedly do not inhabit within innovation (e.g., Pecis, 2016; Pettersson and Lindberg, 2013) or in science and technology contexts (e.g., Chau and Quire, 2018; Sassler et al., 2017; Van Veelen et al., 2019). This defies certain gendered assumptions, putting women in central rather than in marginal 
positions but it does not necessarily obviate difficult gender dynamics within these terrains. The disruption of gendered conventions here which speaks to the disruptions that innovation entails signals the possibilities of thinking differently about innovation than in the established terms of innovation being associated with masculinity.

In this article I focus on one particular form of gendering innovation - its feminising - and what challenges or effects arise from this within one particular field of science, Digital Humanities (DH). DH itself constitutes an innovation in the academy in that it is a relatively new academic domain, particularly in Europe (Griffin and Hayler, 2018). This article takes as its starting point that innovation is conventionally associated with men and masculinity but then argues that some of the connotations of innovation as a concept and a practice mark innovation as feminized. It draws on qualitative empirical research in the form of thirty qualitative professional-life interviews conducted with women and men working in Digital Humanities in Finland, Sweden and Norway in 2017 and 2018. The article dwells on a particular case study of one such worker whose responses were representative of what many informants said, to explore the effects of the feminisation of innovation on those working in Digital Humanities and on the academic field as such.

The article begins with a brief exploration of how men and masculinities have figured in innovation. It then discusses, contrary to the conventional notion of innovation being associated with men and masculinity, why innovation might be connoted as feminised. Following a brief explication of the empirical data collection, the article then analyses the empirical material in the light of this feminization. It draws on Fiona Mackay's (2014) notion of 'nested newness' to explain the gender regime (Acker, 2006) at play here. This is important because innovation and science and technology studies do not occur in a vacuum. They are, as Sheila Jasanoff (2005) for example shows, embedded in organisations and cultures in relation to which they articulate themselves and take on specific forms. Indeed, as innovation research has highlighted repeatedly, innovation is relational (e.g., Knights and Kerfoot, 2004; Pecis, 2016; Pel et al., 2020). Relationality here refers not only to the relations between the different actors involved in innovation or in science and technology (female and male innovators; funders, etc.) but also to non-human factors, processes, and contexts. Hence context matters, and in particular ways as Mackay's concept of 'nested newness' helps to explain. The article provides a feminist analysis of the effects of certain kinds of feminisation on disciplinary innovation in academe. It thereby challenges conventional gendered understandings of innovation at the conceptual level.

\section{INNOVATION, MEN AND MASCULINITY}

We have become very used to thinking of innovation as being associated with the male and with masculinity (e.g., Ahl, 2006; Alsos, Hytti and Ljunggren, 2016: 11-14; Andersson, 2012; Lindberg et al., 2012; Mellström, 2004). This association takes a number of different forms. It is often linked straightforwardly and in binary terms to sex, i.e. the sex of the innovator, for instance, in differentiating between men as innovators and women as not being as innovative as men or as being differently innovative from men (Ahl and Nelson, 2010; Marlow and McAdam, 2013; Nählinder et al., 2012). This derives, at least in part, from a history of assuming that innovation manifests itself predominantly in male-dominated heavy industries and in relation to technology (Ranga and Etzkowitz, 2010: 2). It aligns with the notion that innovation concerns new products and processes, as these occur in maledominated, technology-driven work contexts. However, this view of innovation has been widely challenged in feminist work on innovation, entrepreneurship, and organisation studies (see Acker, 2006; Alsos et al., 2013; Alsos, Hytti and Ljunggren, 2016; Marlow and McAdam, 2013; Pettersson and Lindberg, 2013). Here the emphasis has increasingly been on practices and processes and how these are complexly gendered (Knights and Kerfoot, 2004; Pecis, 2016). Masculinities and femininities continue to be evoked, not least because individual actors have gendered identities but also because attributes associated with masculinities and femininities tend to be ascribed to innovation processes and practices, whether this is in binary or post-binary terms. Pecis and Priola (2019), for example, demonstrate the tenacity of a particular version of masculinity, the 'industrial man', in an Italian biotech research centre where men seek to reconcile their low pay, subjugation to work, and minority status with that old ideal (the 'industrial man'). They do this by devaluing women's competences, women's supposed traits, and simultaneously recasting themselves as 'new industrial men', loyal to their employer, hard-working and constantly available at/for work, whilst also being 'new fathers' and needing to rely on their partners for necessary income. Mackay's theorisations help to explain that tenacity as will be shown below.

\section{THINKING INNOVATION GENDER-DIFFERENTLY: FEMINISING INNOVATION}

Against the common discussion of gender in innovation in terms of binary opposites, a literature has emerged (such as Martin, 2006; Pecis, 2016; Pettersson and Lindberg, 2013) that argues, via the notion of gendering practices and practicing gender, adapted from West and Zimmerman's (1987) 'doing gender', that 'femininities and 
masculinities are not aligned in a binary and oppositional order; rather, their practising is multiple and nondichotomous' (Pecis, 2016: 2119). This itself constitutes a feminist insight that refuses certain forms of binary logic in relation to gender. It opens up the possibility that we might think about innovation as other than aligned with the masculine. This is important for three reasons. First, new and emerging innovation sectors show that different gender dynamics than the conventional ones may be at play (Griffin, 2019; Knights and Kerfoot, 2004; Pecis and Priola, 2019). Second, focussing on conventionally gendered ways of viewing innovation leads to the reproduction of the same and can act as a block to challenging those conventions (Knights, 2015). Third, in challenging conventional gendered notions of innovation we open up the field for new interventions.

My proposition in this article is that innovation as a concept is gendered in specific ways that are different from its conventional association with masculinity (e.g., Pettersson and Lindberg 2013). I shall sketch this gendering here, starting from the proposition that innovation as a concept is gendered feminine. In doing this, I argue implicitly that it is possible to utilise existing categories such as masculine and feminine to challenge their use and utility, as opposed to simply refusing those categories. This also means that I do not think that the use of these categories automatically and inevitably condemns one to binarist thinking as is sometimes implied (see Knights and Kerfoot, 2004; Knights, 2015). Indeed, one might argue that one can only speak from within the discursive frameworks available to us (Butler, 2005). As Judith Butler puts it, "there is no "I" that can stand fully apart from the social conditions of its emergence, no " $\mathrm{I}$ " that is not implicated in a set of conditioning...norms' (2005: 7). However, the existence of those norms and the I's imbrication in them does not condemn that I to the uncritical reproduction of those norms. In appropriating them, and their attendant discourses, the I can exercise critique (Butler, 2005: 17) and in doing so challenge gender binaries through a critical engagement with them. It is in this spirit that I suggest that innovation may be considered feminine, and for the following three theoretical reasons:

1) Innovation is constructed as that which constitutes or makes a difference, a difference from what has gone before. It is 'a new or significantly changed product or process' according to the Oslo Manual (Gault, 2018: 617). It is different. Difference, a much-discussed concept in feminist theory of the 1980s and 1990s (see Braidotti, 1994; Elam, 1994; Flax, 1990), is conventionally attributed to women, to females, to femininity - since difference designates that which deviates from what is culturally taken as the norm, what is dominant. In its difference femininity or femininities has/have been distinguished from masculinity, or masculinities. Difference is then associated with femininity, and hence innovation which is about difference, as a concept, is also associated with femininity.

2) Innovation as difference (new product, new process, new practice) is not about sameness, it is not about retaining the status quo. Instead it is about change, indeed sometimes about challenging the status quo or the hitherto dominant mode. Kaasa (2016) highlights the importance of being able to challenge existing or established ways of thinking and doing as one important key to innovation. Cultures which refuse such possibilities are less innovative.

Innovation, invested in change, is about transformation, gradual or abrupt. Feminism has also been about the idea of change, challenging the status quo, and transformation - the change from hegemonic masculinity to more inclusive forms of interrelation, for example. Hence, I would suggest that innovation as the refusal of sameness, as challenge to the status quo, and as transformation is connoted as feminine, we might even say feminist.

3) Finally, innovation per se is a disruptor, an intervention into established norms (whatever they happen to be). The phrases 'distuptive innovation' (Bower and Christensen, 1995; Christensen, 1997), ${ }^{1}$ and disruptive technologies, much used now, might well be applied to innovation as such, especially if we define technology also in Foucauldian terms to encompass not only new products and processes but also modes of governance and power (Foucault, 2004: 23-41; Behrent, 2013). Women, the feminine, femininity have also been viewed as disruptive of the male order, of the status quo, of certain forms of rationality, etc. Hence innovation as disruptive, and as a disruptive technology in its own right, is also associated with the feminine.

My argument is that the properties conventionally ascribed to innovation, or some of these properties at least, are the same as those conventionally ascribed to women, females, the feminine, femininities - hence my proposition that innovation can be viewed as gendered feminine. As such, innovation is considered both desirable and disruptive - we want it (or her?), and it (she?) needs to be contained. Understanding this helps us to understand the reception of certain kinds of innovation in their specific institutional settings.

To think of innovation as feminine in terms of the three reasons cited above is to evoke a particular form of femininity, disruptive of the masculine order rather than conforming to it. There are, of course, other kinds of femininity - queer gender orders at the very least teach us that (see Halberstam, 2008; Hale and Ojeda, 2018) - but

\footnotetext{
${ }^{1}$ Bower and Christensen (1995) and Christensen (1997) use the phrase 'disruptive innovation' in a particular technical sense (see Christensen et al., 2015) to refer to starting from 'low-end' or 'new-market' footholds. I use 'disruptive innovation' here in a somewhat more general sense although many of the underpinnings of the more technical use also apply.
} 
the one evoked here in its resistance to a hegemonic notion of innovation as masculine might be termed feminist precisely because of its disruptive potential and intent.

\section{DIGITAL HUMANITIES AS INNOVATION}

Given this feminised status of innovation I want to consider a particular innovation in the academy - Digital Humanities or DH for short - and its reception within Nordic universities, and I want to suggest that the very fact that Digital Humanities is an innovation in the academy puts it into a feminised position. Interestingly there is a vast literature on curriculum innovation - a search in google scholar on 28 August 2020 on the topic produced 2 000000 results - but that literature is largely concerned either with pedagogical innovation or with curriculum content innovation. There is much less work that considers disciplinary innovation, here meaning the introduction of a new discipline into the academy. This remains somewhat under-researched, except in terms of 'histories of disciplines.' My focus in this article, however, is on what happens when a new discipline, Digital Humanities, is introduced into higher education. The emergence of $\mathrm{DH}$ as a discipline has, broadly speaking, occurred over the past twenty years or so. It has antecedents in areas such as 'Humanities Computing' and 'Computing for the Humanities'. In the USA DH has become well established (Zorich, 2008) whilst across Europe it largely exists in forums, laboratories, centres, networks and projects (Matres, 2016; Nygren et al., 2015). As will be indicated below, this is important for its status within the academy. I shall now briefly outline the research methods employed in this study and information about my informants before discussing my findings.

\section{RESEARCH METHODS AND INFORMANTS}

Between 2017 and 2018 I conducted 30 semi-structured professional-life interviews with Digital Humanities practitioners, women and men, in Norway, Sweden and Finland, to explore the gendered dimensions of their experiences of working in an emerging discipline and in a technology-driven context. ${ }^{2}$ Participants were purposively selected through searching online staff lists on DH websites at five universities in each of the three selected countries, and through searching research funder websites for staff working in funded DH projects. The key variables were that participants had to work in Digital Humanities, and to interview roughly equal proportions of women and men. In the event 17 women and 13 men were recruited between July 2017 and September 2018. As the Nordic countries have relatively few higher education institutions ${ }^{3}$ and to maintain confidentiality, participants' institutions are not named here. The study involved 17 Swedes (11 women, 6 men), 7 Finns (3 women, 4 men) and 6 Norwegians ( 3 women, 3 men), very roughly in proportion with the difference in population size across the three countries. Their average age range was 44 to 49 . Three participants (two women and one man) were white but had not been born in the Nordic countries; a further participant was of Chinese background but raised in the Nordic countries. All other participants were white. This reflects the dominance of white people in Nordic academe, but also the colonial and immigration histories of the Nordic countries. ${ }^{4}$ All the participants were working in funded DH projects, as directors or research co-ordinators of DH labs or centres, as DH lecturers, systems developers, or programmers.

All participants were interviewed individually, 12 by Skype, and 18 face-to-face. The interviews lasted from 50 minutes to 75 minutes. They were conducted in English. The interviews were transcribed, uploaded into NVivo, and coded using a grounded theory approach (Glaser and Strauss, 1967). This means that the texts were read through carefully multiple times to identify core themes that emerged within them. One significant theme which emerged in this way was the role of gender in the context of working in DH as an emerging academic discipline.

For the purposes of this article I shall draw mainly on the interview with just one female participant. I do this because she was both highly articulate about her experiences and because much of what she said was representative of what I was told by other participants. Her comments thus stand for the gendered experiences professed in different ways by most of my participants. These comments also in various ways reinforce the notion of innovation as gendered feminine as I intend to show.

\footnotetext{
2 This research was funded by Nordforsk (grant no. 81520).

${ }^{3}$ Sweden has $24 \mathrm{HEs}$ able to award third-cycle qualifications (http://english.uka.se/facts-about-higher-education/highereducation-institutions-heis/list-of-higher-education-institutions-in-sweden.html); Finland has 14 universities (http://www.studyinfinland.fi/instancedata/prime_product_julkaisu/cimo/embeds/studyinfinlandwwwstructure/100601_ Higher_Education_Finland_2016_2017.pdf); and Norway has 9 universities (https://www.studyinnorway.no/study-innorway/higher-education-system) - all accessed 19 July 2018.

${ }^{4}$ There is no space to explore this further here, but the Nordic countries have had relatively 'late' immigration, from the 1970s, but mainly from the 1990s onwards (see Pred, 2000).
} 
A little bit about the informant whom I call Sara here: Sara, a researcher in Digital Humanities, was 36 at the time of the interview, in a conflict-ridden relation with her partner who shortly afterwards left her, so that she became a single mum with a very small child. She was one of only 5 women I interviewed who had had a long association with technology. As she put it, 'I was a gamer all my life, I happen to be lucky because there was always technology at home because my brother [21 years older] is a sound engineer.' From him and her father she had inherited technological equipment from an early age. And, typically for the handful of technologically highly adapt and versatile women I met, she had done degrees both in humanities subjects (in her case classics and music) and in computer technology. Unlike the majority of female interviewees who were adept at only one particular technological method such as using eye-movement tracking, or a particular linguistics computer software, which they had come across as adults at university, Sara could range across many different kinds of technology, offer critiques of their structures and applications, and work concretely with computer programming. This was atypical for $75 \%$ of the women I interviewed. Nonetheless, her professional gendered experiences in Digital Humanities mapped very closely onto those of the other women I talked with.

\section{DIGITAL HUMANITIES AS A 'PARADOXICAL SPACE’ OF INNOVATION}

Katarina Pettersson and Malin Lindberg (2013) use Gillian Rose's (1993) work in feminist geography to talk about 'paradoxical spaces' in relation to innovation. They discuss the feminist approaches that have been used to resist hegemonic masculinist discourses regarding innovation in Swedish innovation programs (2013: 324), highlighting four possible approaches. One of these is the movement back and forth between margin and centre. One might argue that $\mathrm{DH}$ as an emerging discipline occupies a central space in knowledge production due to its presence in the university. However, as already indicated above, one of the intriguing dimensions about exploring the establishment of DH in the academy is that to date (2020) across Europe and including in the Nordic countries DH exists almost exclusively in research centres, networks, laboratories, and projects (see Matres, 2016; Nygren et al., 2015). This is significant because such formations are by and large atypical, and hence marginal, for the university which functions mainly by discipline, departments and faculties. This also means that Digital Humanities entities are often marginalised materially and symbolically within universities, meaning that they may lack appropriate physical locations (they may, for example, be located in cellars of buildings, or in other buildings than where their core staff are housed). One of the DH labs that I visited, for instance, was housed in the cellar of a university building where the door leading to the staircase down had a larger sign on it pointing to the toilets than for the DH lab itself. Importantly, these DH entities are also often not represented on key decision-making bodies within their institutions because they do not fit the conventional structural or disciplinary university divisions which institutions utilise for participation in decision-making (such as departmental or faculty boards, representation by discipline, or disciplinary domain). Pettersson and Lindberg (2013) talk about being present and at the same time absent as one of the dimensions of Rose's (1993) paradoxical spaces, or inhabiting the centre and the margins simultaneously. This, one might suggest, is the situation of Digital Humanities as a discipline, which is situated both at a core centre of knowledge production - the university - and simultaneously at its margins in geospatial and symbolic terms. The actual and symbolic space most DH centres in the Nordic countries inhabit is one of marginalisation or institutional, feminised subordination. DH spaces therefore are paradoxical precisely because they - as spaces of disciplinary innovation - are treated in a feminised manner. This has multiple effects on the DH practitioners as I have discussed elsewhere (Griffin, 2019): 1) many DH practitioners do not identify with the physical space provided for them and indeed rarely or never go there; 2) they also have difficulty identifying with $\mathrm{DH}$ as a discipline, and 3) instead they tend to identify with the disciplines into which they were socialised when they first arrived in the academy.

This has to be seen in a context where $\mathrm{DH}$ was not available as a discipline when most of my interviewees were students. Hence their disciplinary socialisation (Becher, 1989) occurred in other disciplines. But the feminised marginalisation of $\mathrm{DH}$ within the space of the university also generates a certain disavowal and distancing by its practitioners who understand their marginalisation quite well. By way of contrast one might want to compare this with the institutionalisation of Women's and Gender Studies where practitioners enthusiastically embraced their new discipline, despite it being treated largely in rather similar ways by the institutions as Digital Humanities is now. One explanation for this is, of course, that Women's and Gender Studies in many countries was set up in explicit opposition to hegemonic science discourses and organisations, offering epistemic and ontological resistance to these, whereas DH and other newly established disciplines such as Health Care do not start from that political position. The point here, however, is that the spatial and symbolic marginalization of Digital Humanities within universities expresses these institutions' ambivalence towards innovation and towards this specific form of innovation in particular. Innovation as expressed through $\mathrm{DH}$ is both desired (the economic and commercial potential of DH's products is recognised) and contained (through how it is positioned), imbuing the discipline with an aura of provisionality and precarity. 
There are, from an institutional point of view, good reasons for this ambivalence: for one thing the humanities through new disciplines such as 'digital humanities' or 'medical humanities' have begun to protest their increasingly marginalised status within many universities and have begun to claim parity with the sciences (Smith, 2016). One way in which this manifests itself is in claims to the need for resources: by scientising themselves in hard sciences fashion the humanities are also laying claim to material needs that go beyond 'pencil and paper', 'chalk and talk', or 'just books'. They are becoming the expensive 'bit on the side' or mistress of academe. This is what my informant Sara, coming from a DH Centre in Sweden, had to say when she described visiting a major Scottish university to give a presentation there:

I walk in there and they just had a frigging projector! You know, they don't have expensive floor screens or with crazy resolutions and immersive sound environments, like we do.

Sara was surprised to find that, unlike in her home institution, this large prestigious university and well-known department did not have anything but very basic technology. However, she also went on to qualify this, revealing how resource need could become a significant problem in her then home university in Sweden:

Not that I'm saying technology was bad for us but it did put a strain on the organization ... so you have for example an expensive screen. The question is, can you use it or do you need a technician for it? Which means technicians become part of the infrastructure and then when you have to apply for money you need the cost to maintain that big bullshit. Sorry! But that's what it is. And is it actually, does it actually help you produce deliverables in your field or is it just there for show? ... the floor screen we had, it's leaking for 3 years and nobody is fixing it because it is more expensive and then we don't use it for anything...

Sara's comments clearly outline what marks Digital Humanities as 'the bit on the side', the marginalised new - it involves ever-evolving technologies whose upkeep and operation require further labour, money, and personnel. Humanities, once the Cinderella of the university, in the form of Digital Humanities is turning into a highmaintenance figure, to which institutions are slow to commit themselves.

Sara's comments also reveal her own contradictory or paradoxical relation to all of this. She both desires and disdains technology because - whilst signalling opportunities for doing research differently - technology constrains her through its material and human requirements, and through the institution's non-response to these requirements.

\section{FEMINISING LABOUR IN INNOVATION IN THE ACADEMY}

DH's marginalisation also impacts on the contractual arrangements of those working in the field. Many Nordic DH practitioners have mosaic or portfolio careers, as indeed did this informant. At the time of the interview Sara had $25 \%$ on one project and:

On the rest, I am doing my own work. XX\% of my own money, you know how it works in Sweden. I was given 50\% from the faculty and in this 50\% I did things that have to do with film, media and the digital aesthetic. So, for the last year I've been writing work separately like tying up loose ends or previous projects...

One might view this way of working as a form of multi-tasking which women are conventionally said to be good at (Stoet et al., 2013). But another way of looking at it is to think of it as fragmenting and dispersing professional identities (Griffin, 2019) whilst upping the workload (since all tasks are accompanied by meetings, paperwork, etc., and the more different tasks one has, the more attendant meetings and paperwork one has to deal with). Much of this is simply unacknowledged in everyday academic labour; here we are back with the unacknowledged, indeed often unpaid labour that is so familiar from discussions of women's work (e.g., Hester, 2018). We might, I suggest, talk of a feminisation of labour within the innovation scene. This goes together with the so-called precarisation of labour (Standing, 2011) that increasingly and disproportionately affects women. My informant, 36 at the time of the interview, had moved from one insecure because time-limited contract, or multiplicity of contracts, to another. She continues to do so even in 2020 . For a single mother with a small child being on time-limited contracts with uncertainty regarding renewal is quite difficult because she is not readily movable - commuting or moving from city to city is not a genuine option for her. In this, my informant was no different from what has been reported by others regarding the pursuit of careers in STEM subjects, for example (Murgia and Poggio, 2019). It was notable among my interviewees that those who had moved, nationally or internationally, were almost all single at the time and did not have children. Especially with younger children, moving proved very tricky. But being able to move, 
especially when one comes from countries with relatively small populations such as the Nordic ones where knowledge-producing personnel and expertise can be more constrained simply as a function of that population size, is vital for advancing one's career.

There was another dimension to the feminisation of labour within DH - a sort of Handmaid's Tale of service, to produce offspring in the form of project applications, publications and other such outputs, all without any form of job guarantee. Universities engage in extractive labour practices, requiring staff in temporary positions to apply for funding from which they may not profit (because the grant is 'owned' by the university) and publications that they may not benefit from (as their contract may be terminated but the publications may still count as part of the university's research productivity). Sara was very vociferous about this experience which she clearly linked intersectionally to status and power asymmetries, seeing herself as a young exploitable woman required to do the bidding of 'old professors' as she called them. This reflects, in micro, or at organisational level, the hierarchist masculinist culture that Hofstede et al. (2010) refer to and that is detrimental to innovation. Sara had not only observed very clearly that young men were more likely to get stable or permanent posts, stating, 'the graduates of my generation...there's at the moment 6 people with permanent jobs, 5 of them are men,' but also noticed how young men seemed to slip into jobs without these necessarily being advertised. More than one male interviewee whom I asked about how he got into his jobs (successive ones) confirmed this - they had been invited into jobs, sometimes even without any particular qualifications in the field. This did not happen to any of my female interviewees. Sara had found herself significantly exploited. She said of one male professor with whom she had worked:

...he never really did anything and then wanted to take all the credit... Previously organising [work] with men has been the same. Organising conferences, edited volumes, anything, it's always been, I did ALL the donkey work, and that makes sense because I was younger I guess. But there comes a time in which you actually want to...say, you know what? It's like household work... Also, men tend to be in my experience less appreciative of your time.

Along with the recognition, well established in feminist thinking, that young women are often treated as the equivalent of housewives in their work situation ('It's like housework'), came also the already semi-internalised agreement that such asymmetry and exploitation at work is somehow appropriate: 'that makes sense because I was younger I guess.' Here we see what Lara Pecis (2016: 2122), following Francine Deutsch (2007), describes as change feeding back into processes of conformity to existing gender norms. These existing gender norms constitute the 'durable inequality' that Charles Tilly first discussed in 1998, where female staff are the objects of exploitation and opportunity hoarding (men and older colleagues preserving their domains for people like themselves).

Sara experienced problems of exploitation specifically with older men, working at the intersection of seniority/status and gender. She eventually came to the realisation that it was easier to work either with men of her own age or, preferably, with women, but as she immediately pointed out, there were few female role models and few women working in her field. At the time of the interview her centre had 12 men and 3 women but one of the women was on maternity leave and the other had just moved to another university following a history of being sexually harassed and professionally disregarded, so effectively Sara was the only woman left.

\section{UNDERSTANDING THE FEMINISATION OF INNOVATION IN THE ACADEMY: A CASE OF 'NESTED NEWNESS'}

How might we then understand the problems Sara faced, the difficulties of institutionalising Digital Humanities as a disciplinary innovation, and its feminisation? To answer this, I draw on Fiona Mackay's (2014) work on 'Nested newness, institutional change, and the gendered limits of change'. Mackay utilises the term 'nested newness' to explain the contradictory gender regimes that govern institutions. She argues that newness is:

nested within a dense institutional environment comprising sets of institutional legacies and ongoing dynamics, including gender regimes that can open and foreclose opportunities for the embedding of innovation (Mackay, 2014: 567).

These institutional legacies and ongoing dynamics are evident in how universities are structured and the privileges that come with conventional organisational forms such as being a department or a faculty rather than a centre. The nestedness of newness is, according to Mackay, also compromised by what she describes as the 'liability of newness', in other words its vulnerabilities and uncertainties (what is it, how will it work, etc.). Institutions can be unwilling to invest in innovations unless they see a clear (economic) return. The mitigation of this liability can result in the reproduction of the norm-i.e., the reproduction of institutional legacies and older orders or gender regimes - what one might describe as 'the tried and the tested.' 
Mackay (2014) suggests that institutions seek to mitigate the liability of newness in two ways: by 'remembering the old' and by 'forgetting the new'. By 'remembering the old' she means that institutions and individuals and groups within them refer, directly or indirectly, to 'how we've always done things' or 'custom and practice' as a bulwark against innovation. 'Forgetting the new' refers to its marginalisation or silencing within academe. The obvious examples in my material here are the reproduction of gendered status and seniority hierarchies between the 'old professor' and the young female researcher which even the young female researcher partially accepts. 'Forgetting the new' at the same time manifests itself in my material in the material and symbolic spatial marginalisation of Digital Humanities as a presence in the academy - by placing centres into marginal spaces you render them forgettable. Mackay (2014) argues that both 'remembering the old' and 'forgetting the new' are ways of seeking acceptance and reaffirming the status quo:

In seeking internal and external credibility and legitimacy, actors in new [figurations] are likely to fall back on authoritative modes - firmly anchored and recognizably so - which tend to be older, more traditional, and hegemonically masculinized rules, gendered norms of appropriateness....and ways of doing things. The liability of newness is therefore gendered. (Mackay 2014: 566)

It is gendered feminine. And this is, indeed, what my material shows.

\section{CONCLUSIONS}

To innovate is to struggle, not least against institutional legacies. Within academe, the imperative and rhetoric to produce original research and advance knowledge, to produce solutions for the challenges that societies face, and to conduct 'world-class' research create opportunities for innovation. In this sense, innovation is desired. However, this also occurs within existing institutional frameworks and gender regimes in which the new tends to have to compete with the established for both space and recognition, or in Nancy Fraser's (1995) terms, for redistribution of resources and recognition. Here constraints come into play. Without recognition, the redistribution of resources is unlikely to occur. In this scenario the new can easily be made to occupy a feminised position, one of marginalisation and subservience, until it has proven its worth. But this can be difficult to achieve from a position of marginalisation where resource needs, for example, are ignored. Mackay's depiction of 'nested newness' with its mechanisms of 'remembering the old' and 'forgetting the new' as props to mitigate the liability of newness aptly depicts what can happen to disciplinary innovation as it hits the buffers of institutional legacies. This is clearly one of the major challenges that innovation faces. It is an effect of the feminised position in which newly emerging disciplines in academe can find themselves, one of spatial and symbolic marginalisation. This clearly retards innovation and the opportunities that innovation, including innovation of academic disciplines, offers. When institutions, for example, find it difficult to commit to the provision and support of the necessary technology and person power to enable new disciplines to operate effectively, these disciplines' innovation potential is undermined. The challenge that $\mathrm{DH}$ poses to the status of the humanities in the academy as 'poor relation' has yet to be met. Expensive but unusable equipment is just one expression of this. Working under such conditions can be demoralising for staff, and may drive them back into more traditional disciplines, as was the case with a number of my informants, thus further undermining the innovation potential of new disciplines but also negating any investments already made. Further, the working conditions for staff as such with their attendant extractive practices (see also Murgia and Poggio, 2019) need to be addressed.

These issues are not specific to Digital Humanities as a new discipline, but one might argue that they are exacerbated when the new is freighted by the fact that a sizeable proportion of staff are female as is the case in emerging fields such as DH but also Health Technology and Medical Humanities, for example. Here entrenched gender regimes, underpinned by masculinist hierarchical institutional cultures, manifest themselves through the spatial and symbolic marginalisation of these new disciplines as discussed above. Challenging these is one of the challenges for STS.

To end on a positive note: This does not mean that all innovation is futile or doomed to the reproduction of the same by its context. Sara's positive experiences of collaborating with men her own age as well as with women suggest possibilities for change even despite the stickiness - to use Sara Ahmed's (2004) term - of gendered institutional legacies.

\section{ACKNOWLEDGMENTS}

The author gratefully acknowledges the support of Nordforsk (grant no. 81520) for the Centre of Excellence, Nordwit, under whose auspices this research was conducted. The author would also like to thank the two anonymous reviewers for their helpful comments. 


\section{REFERENCES}

Acker, J. (2006). Inequality Regimes: Gender, Class, and Race in Organizations. Gender \& Society, 20(4), 441-464. https://doi.org/10.1177/0891243206289499

Ahl, H. (2006). Why Research on Women Entrepreneurs Needs New Directions. Entrepreneurship Theory and Practice, 30(5), 595-621. https:// doi.org/10.1111/j.1540-6520.2006.00138.x

Ahl, H. and Marlow, S. (2012). Exploring the Dynamics of Gender, Feminism, and Entrepreneurship: Advancing Debate to Escape a Dead End? Organization Science, 19(5), 543-562. https://doi.org/10.1177/1350508412448695

Ahl, H. and Nelson, T. (2010). Moving Forward: Institutional Perspectives on Gender and Entrepreneurship. International Journal of Gender and Entrepreneurship, 2(1), 5-9. https:// doi.org/10.1108/17566261011044259

Ahmed, S. (2004). The Cultural Politics of Emotion. Edinburgh: Edinburgh University Press.

Alsos, G. A., Hytti, U. and Ljunggren, E. (2013). Gender and Innovation: State of the Art and a Research Agenda. International Journal of gender and Entrepreneurship, 5(3), 236-256. https:/ / doi.org/10.1108/IJGE-06-2013-0049

Alsos, G. A., Hytti, U. and Ljunggren, E. (2016). Gender and Innovation-An Introduction, in E. Ljunggren, G. A. Alsos, U. Hytti (eds), Research Handbook on Gender and Innovation. Cheltenham: Edward Elgar Publishing. https://doi.org/10.4337/9781783478132

Alsos, G. A., Hytti, U., Ljunggren, E., Rönnblom, M. and Keisu, B. I. (2013). Constructions of Innovation and Gender (Equality) in Swedish Universities. International Journal of Gender and Entrepreneurship, 5(3), 342-356. https://doi.org/10.1108/IJGE-09-2012-0047

Andersson, S., Berglund, K., Gunnarsson, E. and Sundin, E. (2012). Promoting Innovation: Policies, practices, and procedure. Stockholm: Vinnova.

André, I. (2013). Gender and Social Innovation: The Role of EU Policies, in F. Moulaert, D. MacCallum, A. Mehmood and A. Hamdouch (eds), The International Handbook on Social Innovation: Collective action, social learning and transdisciplinary research (pp. 412-423). Cheltenham: Edward Elgar Publishing.

Becher, T. (1989). Academic Tribes and Territories: Intellectual enquiry and the culture of disciplines. London: Society for Research into Higher Education.

Behrent, M. C. (2013). Foucault and Technology. History and Technology, 29(1), 54-104. https://doi.org/10.1080/07341512.2013.780351

Blake, M. K. and Hanson, S. (2005). Rethinking Innovation: Context and Gender. Environment and Planning A, 37(4), 681-701. https://doi.org/10.1068/a3710

Bower, J. L. and Christensen, C. M. (1995). Disruptive Innovation: Catching the Wave. Harvard Business Review, 73, 43-45.

Braidotti, R. (1994). Nomadic Subjects. New York: Columbia University Press.

Buse, K. (2018). Women's Under-Representation in Engineering and Computing: Fresh Perspectives on a Complex Problem. Frontiers in Psychology, 9, 595. https://doi.org/10.3389/fpsyg.2018.00595

Chau, V. S. and Quire, C. (2018). Back to the Future of Women in Technology: Insights from Understanding the Shortage of Women in Innovation Sectors for Managing Corporate Foresight. Technology Analysis \& Strategic Management, 30(6), 747-764. https://doi.org/10.1080/09537325.2017.1376046

Christensen, C. (1997). The Innovator's Dilemma. Cambridge, MA: Harvard Business School Press.

Christensen, C. M., Raynor, M. E. and McDonald, R. (2015). What is Disruptive Innovation. Harvard Business Review, 93(12), 44-53.

Deutsch, F. M. (2007). Undoing Gender. Gender \& Society, 21(1), 106-127. https://doi.org/10.1177/0891243206293577

Elam, D. (1994). Feminism and Deconstruction: Ms. en abyme. London: Routledge.

Ernst, W. and Horwath, I. (2013). Gender in Science and Technology: Interdisciplinary approaches. Bielefeld: transcript Verlag. https://doi.org/10.14361/transcript.9783839424346

Flax, J. (1990). Thinking Fragments. Berkeley: University of California Press. https://doi.org/10.1525/9780520329409

Foucault, M. (2004). Society Must Be Defended: Lectures at the College de France, 1975-76 (trans. D. Macey). London: Penguin.

Fox, M. F., Whittington, K. and Linkova, M. (2017). Gender, (In)Equity, and the Scientific Workforce, in U. Felt, R. Fouché, C. A. Miller and L. Smith-Doerr (eds), Handbook of Science and Technology Studies, $4^{\text {th }}$ ed. (pp. 701-732). Cambridge, MA: MIT Press.

Fraser, N. (1995). From Redistribution to Recognition? Dilemmas of Justice in a 'Post-Socialist' Age. New Left Review, 212, 68-149.

Garud, R., Tuertscher, P., and Van de Ven, A.H. (2013). Perspectives on Innovation Processes. Academy of Management Annals, 7(1), 775-819. https://doi.org/10.5465/19416520.2013.791066 
Gault, F. (2018). Defining and Measuring Innovation in all Sectors of the Economy. Research Policy, 47, 617-622. https://doi.org/10.1016/j.respol.2018.01.007

Glaser, B., and Strauss, A. (1967). The Discovery of Grounded Theory: Strategies for qualitative research. Mill Valley, CA: Sociology Press. https:// doi.org/10.1097/00006199-196807000-00014

Griffin, G. (2019). Intersectionalized Professional Identities and Gender in the Digital Humanities in the Nordic Countries. Work, Employment and Society, 33(6), 966-982. https://doi.org/10.1177/0950017019856821

Griffin, G. and Hayler, M. (2018). Collaboration in Digital Humanities: Persisting Silences. Digital Humanities Quarterly, 12(1). Available at: http://digitalhumanities.org/dhq/vol/12/1/000351/000351.html. (Accessed 13 May 2021).

Halberstam, J. (2008). Female Masculinity. Durham: Duke University Press.

Hale, S. E. and Ojeda, T. (2018). Acceptable Femininity? Gay Male Misogyny and the Policing of Queer Femininities. European Journal of Women's Studies, 25(3), 310-324. https://doi.org/10.1177/1350506818764762

Hearn, J. and Husu, L. (2011). Understanding Gender: Some Implications for Science and Technology. Interdisciplinary Science Reviens, 36(2), 103-113. https:// doi.org/10.1179/030801811X13013181961301

Henwood, F. and Miller, K. (2001). Boxed In or Coming Out? On the Treatment of Science, Technology and Gender in Educational Research. Gender and Education, 13(3), 237-242. https://doi.org/10.1080/09540250120063535

Hester, H. (2018). Care Under Capitalism: The Crisis of 'Women’s Work'. IPPR Progressive Review, 24(4), 343-352.

Hofstede, G., Hofstede, G. J. and Minkov, M. (2010). Cultures and Organisations: Software of the mind. New York: McGraw Hill.

Jasanoff, S. (2005). Designs on Nature: Science and democracy in Europe and the United States. Princeton: Princeton University Press. https:// doi.org/10.1515/9781400837311

Kaasa, A. (2016). Culture and Innovation: Evidence from the European Union and Neighbouring Countries. Tidschrift voor economische en sociale geografie, 108(1), 109-128. https:// doi.org/10.1111/tesg.12194

Knights, D. (2015). Binaries Need to Shatter for Bodies to Matter: Do Disembodied Masculinities Undermine Organizational Ethics? Organization, 22(2), 200-216. https://doi.org/10.1177/1350508414558724

Knights, D. and Kerfoot, D. (2004). Between Representations and Subjectivity: Gender Binaries and the Politics of Organizational Transformation. Gender, Work and Organization, 11(4), 430-454. https://doi.org/10.1111/j.1468-0432.2004.00241.x

Lindberg, M. (2012). A Striking Pattern: Co-Construction of Innovation, Men and Masculinity in Sweden's Innovation Policy, in S. Andersson, K. Berglund, E. Gunnarsson and E. Sundin (eds), Promoting Innovation: Policies, practices, and procedure (pp. 47-67). Stockholm: Vinnova.

Lindberg, M., Forsberg, L. and Karlberg, H. (2015). Gendered Social Innovation: A Theoretical Lens for Analysing Structural Transformation in Organisations and Society. International Journal of Social Entrepreneurship and Innovation, 3(6), 472-483. https://doi.org/10.1504/IJSEI.2015.073540

Lindberg, M., Forsberg, L. and Karlberg, H. (2016). Gender Dimensions in Women's Networking for Social Innovation. Innovation: The European Journal of Social Science Research, 29(4), 410-423. https://doi.org/10.1080/13511610.2016.1166037

Mackay, F. (2014). Nested Newness, Institutional Innovation, and the Gendered Limits of Change. Politics and Gender, 10, 549-571. https://doi.org/10.1017/S1743923X14000415

Maestripieri, L. (2017). Does Social Innovation Reduce the Economic Marginalization of Women? Insights from the Case of Italian Solidarity Purchasing Groups. Journal of Social Entrepreneurship, 8(3), 320-337. https:// doi.org/10.1080/19420676.2017.1364289

Marlow, S. and McAdam, M. (2012). Analysing the Influence of Gender upon High-Technology Venturing Within the Context of Business Incubation, Entrepreneurship Theory and Practice, 36(4), 655-676. https:// doi.org/10.1111/j.1540-6520.2010.00431.x

Matres, I. (2016). Report on the DARIAH Digital Practices in the Arts and Humanities Survey 2016. Helsinki: University of Helsinki.

Mellström, U. (2004). Machines and Masculine Subjectivity: Technology as an Integral Part of Men's Life Experiences. Men and Masculinities, 6(4), 368-382. https://doi.org/10.1177/1097184X03260960

Murgia, A. and Poggio, B. (eds). (2019). Gender and Precarious Research Careers: A comparative analysis. London: Routledge. https://doi.org/10.4324/9781315201245

Nählinder, J., Timmar, M. and Wigren-Kristoferson, C. (2012). Are Female and Male Entrepreneurs Equally Innovative? Reducing the Gender Bias of Operationalisations and Industries Studied, in S. Andersson, K. Berglund, J. G. Torslund, E. Gunnarsson and E. Sundin (eds), Promoting Innovation: Policies, practices and procedures (pp. 351-372). Stockholm: Vinnova.

Nnachi, N. O. and Okpube, M. N. (2015). Psycho-Social Determinants of Gender Prejudice in Science, Technology, Engineering and Mathematics. Journal of Education and Practice, 6(17), 190-194. 
Nygren, T., Foka, A. and Buckland, P. (2015). The Status Quo of Digital Humanities in Sweden: Past, Present and Future of Digital History, in T. Kahlert and C. Prinz (eds), The Status Quo of Digital Humanities (pp. 7-39). Berlin: Clio-online. Available at: https://edoc.hu-berlin.de/bitstream/handle/18452/19490/HistFor_162015.pdf?sequence=1. (Accessed 24 August 2020).

Pecis, L. (2016). Doing and Undoing Gender in Innovation: Femininities and Masculinities in Innovation Processes. Human Relations, 69(11), 2117-2140. https:/ / doi.org/10.1177/0018726716634445

Pecis, L. and Priola, V. (2019). The 'New Industrial Man' as Unhero: Doing Postfeminist Masculinities in an Italian Pharmacological Research Centre. Gender, Work and Organization, 26, 1413-1432. https://doi.org/10.1111/gwao.12359

Pel, B., Haxeltine, A., Avelino, F., Dumitru, A., Kemp, R., Bauler, T., ... and Jørgensen, M. S. (2020). Towards a Theory of Transformative Social Innovation: A Relational Framework and 12 Propositions. Research Policy, 49(8), 104080. https://doi.org/10.1016/j.respol.2020.104080

Pettersson, K. and Lindberg, M. (2013). Paradoxical Spaces of Feminist Resistance: Mapping the Margin to the Masculinist Innovation Discourse. International Journal of Gender and Entrepreneurship, 5(3), $323-341$. https://doi.org/10.1108/IJGE-09-2012-0039

Pred, A. (2000). Even in Sweden. Berkeley: University of California Press. https://doi.org/10.1525/9780520925281

Ranga, M. and Etzkowitz, H. (2010). Athena in the World of Techne: The Gender Dimension of Technology, Innovation and Entrepreneurship. Journal of Technology Management and Innovation, 5(1), 1-12. https://doi.org/10.4067/S0718-27242010000100001

Roberts, K. (2014). Engaging More Women and Girls in Mathematics and STEM Fields: The international evidence. Report for the Australian Mathematical Sciences Institute. Available at: https://amsi.org.au/?publications=genderreport-20104. (Accessed 21 April 2021).

Rose, G. (1993). Feminism and Geography: The limits of geographical knowledge. Minneapolis: University of Minnesota Press.

Sassler, S., Glass, J., Levitte, Y. and Michelmore, K. M. (2017). The Missing Women in STEM? Assessing Gender Differentials in the Factors Associated with Transition to First Jobs. Social Science Research, 63, $192-208$. https://doi.org/10.1016/j.ssresearch.2016.09.014

Schiebinger, L. (1999). Gender Studies of STS: A Look Toward the Future. Science, Technology and Society, 4(1), 95106. https://doi.org/10.1177/097172189900400107

Siann, G. and Callaghan, M. (2001). Choices and Barriers: Factors Influencing Women's Choice of Higher Education in Science, Engineering and Technology. Journal of Further and Higher Education, 25(1), 85-95. https://doi.org/10.1080/03098770020030524

Smith, B. H. (2016). Scientizing the Humanities: Shifts, Collisions, Negotiations. Common Knowledge, $22(3), 353-372$. https://doi.org/10.1215/0961754X-3622212

Standing, G. (2011). The Precariat: The new dangerous class. London: Bloomsbury.

Stoet, G., O'Connor, D. B., Conner, M. and Laws, K. R. (2013). Are Women Better Than Men at Multi-Tasking? BMC Psychology, 1(1), 18. https://doi.org/10.1186/2050-7283-1-18

Sundin, E. (2012). Entrepreneurship, Innovation and Gender: The Construction of Projects for Entrepreneurship and Innovation in the Healthcare and Care Sectors, in S. Andersson, K. Berglund, E. Gunnarsson and E. Sundin (eds), Promoting Innovation: Policies, practices and procedures (pp. 155-172). Stockholm: Vinnova.

Tilly, C. (1998). Durable Inequality. Berkeley: University of California Press. https://doi.org/10.1525/9780520924222

Van Veelen, R., Derks, B. and Endedijk, M. D. (2019). Double Trouble: How Being Outnumbered and Negatively Stereotyped Threatens Career Outcomes of Women in STEM. Frontiers in Psychology, $10,150$. https://doi.org/10.3389/fpsyg.2019.00150

Wajcman, J. (2000). Reflections on Gender and Technology Studies: In What State is the Art? Social Studies of Science, 30(3), 447-464. https:/ / doi.org/10.1177/030631200030003005

Wajcman, J. (2007). From Women and Technology to Gendered Technoscience. Information, Community and Society, 10(3), 287-298. https:/ / doi.org/10.1080/13691180701409770

Wajcman, J. (2010). Feminist Theories of Technology. Cambridge Journal of Economics, 34(1), $143-152$. https://doi.org/10.1093/cje/ben057

Washington: Council on Library and Information Resources. Available at: https://www.clir.org/wpcontent/uploads/sites/6/pub143.pdf. (Accessed 20 July 2020).

West, C. and Zimmerman, D. H. (1987). Doing Gender. Gender \& Society, 1(2), $125-151$. https://doi.org/10.1177/0891243287001002002

Zorich, D. M. (2008). A Survey of Digital Humanities Centers in the United States. 
Citation: Griffin, G. (2021). Feminising Innovation: Challenges in Science and Technology Studies (STS). Feminist Encounters: A Journal of Critical Studies in Culture and Politics, 5(2), 24. https://doi.org/10.20897/femenc/11161

Copyright (C) 2021 by Author/s and Licensed by Lectito BV, Netherlands. This is an open access article distributed under the Creative Commons Attribution License which permits unrestricted use, distribution, and reproduction in any medium, provided the original work is properly cited. 